\title{
Costa Rica en la geopolítica de la Santa Sede. La representación papal en Centroamérica entre 1908-1936
}

\section{José Aurelio Sandi-Morales}

Máster en Historia de la Universidad Nacional. Profesor de Historia en la Universidad Nacional, miembro del Instituto de investigaciones Bernardo Augusto Thiel. Doctorando de la Scuola Normale Superiore di Pisa, Italia, con una tesis que versa sobre las relaciones políticas, diplomáticas y clericales entre la Santa Sede y el Costa Rica entre 1870-1936. Ha publicado varios artículos sobre las relaciones entre la jerarquía de la Iglesia católica y el Estado costarricense en el periodo liberal. Su tesis de Maestría fue publicada con el título: Estado e Iglesia católica en Costa Rica 1850-1920; en los procesos de control del espacio geográfico y la creación de un modelo de costarricense. Universidad Nacional. Costa Rica.

jasm77historia@gmail.com

Recibido: 13 de octubre, 2015 • Aceptado: 29 de marzo, $2016 \quad$ • Corregido: 29 de julio, 2016

RESUMEN

(Find the abstracts in English and French at the end of the article)

El artículo que se presenta le ofrece al lector un panorama del origen, desarrollo y papel de los representantes papales enviados por la Santa Sede a Centroamérica entre 1908-1936. Se analizarán cuáles eran los motivos, funciones y tareas que Roma les asignaba a estos enviados. Se expondrá cómo a través de sus informes era analizada Centroamérica desde diversos puntos de vista: económicos, sociales, culturales, militares y hasta electorales. Esto último le permitió a la Santa Sede tener un panorama amplio y claro de las situaciones que enfrentaba la región. El periodo de estudio se justifica porque en 1908 se creó la primera delegación apostólica en América Central y es hasta 1936, a causa de ser el último año, que se pueden consultar documentos en los Archivos Vaticanos.

Palabras clave: Santa Sede, enviados Papales, internunciatura, nuncios, romanización del clero.

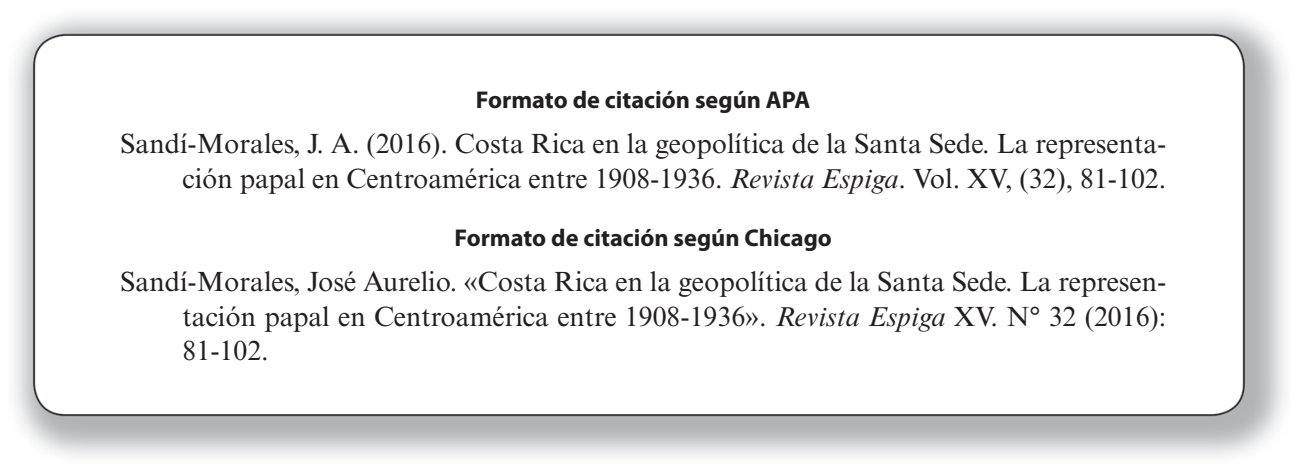




\section{Introducción ${ }^{1}$}

Para poder explicar de mejor manera el tema propuesto en este trabajo es indispensable tener claro tres títulos que la Santa Sede confería a sus enviados y tres conceptos teóricos fundamentales para entender el periodo de estudio. Por un lado, se debe definir qué era un delegado apostólico, un internuncio y un nuncio, puesto que estos fueron los apelativos que recibieron los enviados papales en América Central durante el período de estudio. A la vez, se vuelve imperioso definir conceptos como laicización, secularización y romanización del clero. Estas definiciones se vuelven fundamentales, porque será entorno a ellas que gire y se explique el interés de Roma por enviar a sus representantes a esta región, así el cómo y el porqué del accionar de estos.

Explicar qué era un delegado apostólico, internuncio y nuncio es necesario debido a que el representante papal para América Central cambió de título tres veces. De 1908 a 1915, el enviado papal para la región tuvo el título de delegado apostólico, entre 1917 y 1933, el apelativo que lo hacía acompañar era de internuncio y de 1933 a 1936, fin del período de estudio, el título del cual gozaba era el de nuncio apostólico.

Se debe tener claro que los representantes del Papa no fueron una práctica nueva, ni fueron creados para el caso específico de América Central. Basta mencionar que para los concilios de Nicea (335 d.C.) y Constantinopla (381 d.C.), el obispo de Roma no asistió, más bien envió a varios de sus representantes (Alberigo, 1993: 28 y 56). Tampoco estos representantes tuvieron un solo nombre a través de la historia, ya que desde los inicios del cristianismo existieron los legados pontificios, los apocrisiarios papales, los vicarios apostólicos, los legados misionales, el legatus romanus, los legati a latere, los legati missi, los legatinati y los ya mencionados delegados apostólicos, internuncios y nuncios apostólicos (Feldkamp, 2004). De igual manera, las legaciones pontificias en el continente americano no fueron nuevas para Roma, ya que para el bienio 1823-1824 se había enviado por parte de Pio VII la denominada "Missione Muzi-Mastai" a Chile para ver la posibilidad de establecer relaciones diplomáticas entre las recién independizadas repúblicas y la Santa Sede (Martina, 1994, 149-193). De igual manera, como ya se ha mencionado, existían delegados e internuncios en otras partes del Nuevo Mundo, como Brasil, Colombia, México, entre otras regiones de este continente ${ }^{2}$.Para el presente trabajo importan

1. El presente artículo es solo un extracto y sin concluir del todo de la tesis doctoral que el autor realizó en la Scuola Normale Superiore di Pisa, en Italia. El tema de investigación que se plantea acá requirió (por más de dos años) la consulta de los Archivos Vaticanos (Archivio Vaticano Segreto y Archivio degli Affari Ecclesiastici), de las congregaciones de los Jesuitas, Dominicos, Paulinos (París y Roma). La totalidad de las fuentes primarias que se menciona de dichos archivos son inéditas para la historiografía costarricense.

2. El orden de creación de Internunciaturas y Nunciaturas para América es la siguiente: Brasil 1829, Colombia en 1863, Chile 1840, Estados Unidos entre 1848-1867, Delegación Apostólica en 1893 y de nuevo una nunciatura en 1984 hasta la actualidad, México 1864, Argentina, Bolivia, Chile (de nuevo), Ecuador, Paraguay, Perú y Uruguay 1877, República Dominicana 1881, Venezuela y Haití en 1891, Costa Rica Honduras y Nicaragua en 1908 (con sede en Costa Rica), el Salvador en 1922, Panamá 1923 (Eran el mismo que tenía sede en Costa Rica) y Guatemala en 1936. (Feldkamp, 2004; 73-74, 76-78, 82 y 99-100) Hay que dejar claro que estas representaciones fueron cerradas y de nuevo abiertas, según fuera la historia de cada país, en especial con la llegada de los liberales del "segundo liberalismo latinoamericano" luego de la década de 1860, como por ejemplo la de México que se inauguró en 1864 y ya en 1865 estaba cerrada por la expulsión del nuncio a manos de los liberales como Juárez y hasta del propio Maximiliano de Habsburgo. 
solo los tres últimos títulos, por ende se pasará a conceptualizarlos y dejar claro cuáles eran sus funciones y rangos de poder.

Los delegados apostólicos eran los encargados de dirigir "una legación permanente en determinados países, pero estaban designados únicamente para ejercer supervisión eclesiástica y enviar los correspondientes informes" que solicitaba Roma sobre los estados de las diócesis y el país en los que se ejercían sus cargos. Por su parte, los nuncios apostólicos y los internuncios (estos últimos residían en lo que se consideraban Estados pequeños, como por ejemplo Costa Rica, Nicaragua, Honduras, Holanda o Luxemburgo), eran "legados permanentes ante los Gobiernos nacionales. Tenían una doble tarea: mantener las relaciones diplomáticas entre la Santa Sede y los gobiernos seculares y supervisar la vida eclesiástica del territorio de su jurisdicción enviando al Papa los correspondientes informes" (Feldkamp, 2004, 79). Estas obligaciones quedaron bien establecidas por el propio Codex Iuris Canonici, promulgado en 1917. (Codex Iuris Canonici, 1917, 72) Se debe tener claro que existía una diferencia entre un internuncio y un nuncio, como se ha dicho, los internuncios eran residentes de pequeños Estados, mientras que el nuncio era nombrado en un territorio que la Santa Sede consideraba primordial en sus relaciones diplomáticas. Este hecho provocaba que existieran nunciaturas de primera y segunda categoría. Un ejemplo de primera categoría era Madrid, Lisboa, París, Múnich y Brasil; de segunda, Argentina, Colombia, Perú y Costa Rica cuando fue creada con esta denominación en 1933 (Feldkamp, 2004, 79).

Ahora bien, se vuelve imperioso conceptualizar lo siguientes términos: laicismo, secularización y romanización del clero, pues estos conceptos, como se ha indicado, son elementales para comprender las labores desarrolladas por los delegados papales. Las revoluciones modernas, sea la inglesa, la estadounidense o la francesa cambiaron el modo de percibir el poder político. Este dejó de ser por designación divina y se convirtió en una elección de las "masas". Los nuevos poderes políticos civiles no vieron siempre con agrado la relaciones entre la esfera de poder civil con la eclesial. Por ende, empezaron un proceso largo, pero continuo de separación de poderes, en el cual se buscaba la desaparición de la antigua unión Estado-Iglesia y así permaneciera únicamente el marco de acción de la Iglesia en el interior de sus templos, ya fueran católicos, luteranos, anglicanos, calvinistas y demás denominaciones.

Después de 1870, con la llegada del segundo liberalismo a América Central, los liberales en Guatemala, El Salvador, Honduras, Nicaragua y Costa Rica, más temprano que tarde, iniciaron la declaratoria de una serie de normas conocidas como las leyes anticlericales. Estas, a grandes rasgos, establecieron la desamortización de las tierras que le quedaban a la Iglesia católica luego de la primera enajenación dada a finales del siglo XVIII e inicios del XIX. Como consecuencia también acarreó con la expulsión de los obispos y de las órdenes religiosas, laicización de la educación y por ende la prohibición a la fe católica a participar en ésta. Además, este cambio provocó la secularización de los cementerios y ruptura de los Concordatos negociados con la Santa Sede entre las décadas de 1850-1860.

Todo esto perseguía la consolidación del laicismo, el cual no se explica, sino se ve en unión con la secularización de las sociedades. A la vez se debe de aclarar que no en todos los países este proceso se llevó a cabo de la misma manera o se consolidó realmente. Por 
ejemplo, no se puede comparar lo acaecido en Guatemala con lo sucedido en Costa Rica durante las mismas décadas de 1870 a 1930.

El laicismo para la segunda mitad del siglo XIX entendía que el Estado debía ser "neutral ante las confesiones religiosas y tolerante con todas ellas" (Arboleda, 2006, 72) Unido a esto, aparecía otro término fundamental: la libertad religiosa. Esta proponía que cada individuo era libre de profesar la fe que quisiese sin ser obligado por el propio Estado o por un grupo de personas pertenecientes a un culto en particular. Por ejemplo, Jonh Locke afirmaba que el Estado no podía imponer una religión, porque ello significaría estar en contra de la libertad religiosa (Fraile, 1999, 70).

Por su parte, la secularización no puede ser vista como un concepto en sí mismo, sino más bien como la culminación de un proceso que buscaba la laicidad del Estado. Por ende, la secularización solo se puede entender en unión y paralelo con el laicismo (Blancarte, 2008, 20). La secularización, según lo explicado por Di Stefano, se puede ver cuando sucede: "una pérdida de la referencia religiosa de concepciones, instituciones o funciones sociales que provocan ciertos procesos políticos (como la formación del Estado), económicos (como la expansión de las formas de propiedad capitalista) o sociales (como las migraciones de masas)". Proceso que se consolidaba cuando: "las nociones de soberanía y de ciudadanía, que a lo largo del siglo XIX pierden sus connotaciones religiosas". (Di Stefano, 2011, 1) Entonces, se considera la culminación del proceso de secularización de la sociedad cuando se da una real separación entre la Iglesia y el Estado. Acción con la cual la jerarquía católica, tanto regional como romana, no estaba de acuerdo con que sucediera y por ende envió a sus representantes para evitarlo o subsanar los problemas que esta generó cuando se dio en varios países.

De frente a este proceso que se inició en Europa y se extendió rápidamente por América, en especial luego de 1870 en América Central, la jerarquía católica no se quedó de brazos cruzados y actuó. Esto fue realizado mediante un proceso que llegó a ser denominado como la romanización del clero. Este accionar se puede conceptualizar como la nueva centralización y consolidación del poder dentro del catolicismo en la Curia Romana y especialmente en la figura del Papa, del Santo Padre (Rusconi, 2010, 341-558). Esta centralización del poder se caracterizaba por un apego irrestricto a lo decretado por esta autoridad espiritual.

La romanización del clero buscaba darle de nuevo a la Iglesia católica un carácter de prestigio y fortaleza ante las críticas que recibía de los diversos modos de pensar, los cuales en las revoluciones modernas encontraron cobijo (liberalismo, masonería, deísmo, racionalismo, entre otros). Para la cúpula del poder católico era indispensable dejar en claro que el catolicismo romano era la institución que tenía los medios para la salvación del alma. Esto en contraposición a otras doctrinas, y que al estar comandada por la Santa Sede se oponía a cualquier movimiento político, social o económico que alterara las estructuras de poder, así como que pusieran en duda sus verdades ya establecidas.

La romanización del clero, entonces, buscaba afianzar la universalización de la fe católica, pero siempre centralizada en el poder del Romano Pontífice, del cual dependían todas las decisiones que se tomaran. Para conseguir esto, la Iglesia inició un proceso para fortalecer la idea que la institución eclesial apareció en el mundo por fundación divina, 
lo que la hacía esencialmente superior a las demás instituciones políticas y sociales existentes (Azzi, 1994, 64). Unido a esto, se reforzaba la figura del Papa como el jefe supremo del catolicismo. Este sin duda alguna tenía todo el poder y autoridad dentro de la Iglesia católica a finales del siglo XIX, gracias a declaraciones como la infalibilidad papal, establecida en el Concilio Vaticano I (Martina, 1974). Para dar más fuerza a esto, Roma inició un proceso de entrega vertical de poder a sus principales actores, siempre y cuando estos no se alejaran de la autoridad absoluta del Papa.

Lo dicho en los dos párrafos anteriores se consolida cuando la Santa Sede empodera a los obispos, dándoles con mayor fuerza apelativos como jefes del catolicismo del territorio por ellos pastoreados. Esto lo consiguió al no admitir cuestionamiento o impugnaciones a determinaciones que los prelados hubiesen tomado, siempre y cuando fuera dentro de los márgenes que Roma establecía como ideales y propicios. De igual manera la Santa Sede propuso la exaltación del clero a los laicos, mediante la presentación del sacerdote como un ser superior a los demás, el cual tenía la privilegiada misión de hacer de intermediario entre Dios-Hijo y la humanidad y viceversa (Azzi, 1994, 69).

El proceso no terminó ahí, debido a que la Iglesia "premiaba" con prestigio a los católicos practicantes, pues consideraba como modelos a seguir a los católicos que tuvieran una práctica sacramental continua, que comulgaran semanalmente y que fueran sujetos a la autoridad del presbítero. Este estaría en unión con su obispo y este último hermanado con el Romano Pontífice, quien presidía en caridad.

Es bajo estos conceptos que se debe analizar la intención por parte de la Curia Romana de tener representantes en estas tierras. Los enviados papales serían los encargados de velar y analizar el grado de avance que se obtuviera en cada país centroamericano con los procesos de laicización y secularización, y así buscar cómo detenerlos o minimizar sus efectos en la sociedad. También debían fiscalizar y organizar la adhesión de los fieles, el clero y el episcopado regional a la autoridad suprema del Papa, en sí consolidar la denominada romanización del clero. Por último, debían fortalecer a toda costa las relaciones diplomáticas entre la Santa Sede y los gobiernos civiles de la región, lo cual era una de sus principales tareas.

\section{El origen de una "casa" para el representante del Papa en América Central}

La creación de una Internunciatura en Centroamérica era un paso fundamental para la región, pero también de importancia para la Santa Sede. Esta, luego de la "presa di Roma"3, del 20 de setiembre de 1870, había perdido por completo el poco territorio que le quedaba a su haber de los antiguos Estados Pontificios, que en sí era solo la ciudad de Roma. Esto internacionalmente la dejaba en una desventaja enorme en contraposición a las nuevas potencias y al nuevo orden mundial. Roma había perdido su poderío y buscaba de una u otra manera ser reconocida por diversos países, reinos y regiones aún como un Estado independiente.

3. La toma de Roma consistió en la entrada de los "bersaglieri” de la Corte Monárquica de los Savoia, para apropiarse del último tracto de territorio que les hacía falta para la unificación total de la Península Itálica. Este hecho se dio el 20 de setiembre de 1870. 
La intención de crear en algún país de Centroamérica un puesto para el representante del Papa en la región data de muchos años antes de su creación, en 1908. La Santa Sede, así como muchos de los nuevos estados independientes de América, en su afán por encontrar el respaldo y reconocimiento internacional como Estados independientes, pactaron el reconocimiento mutuo de Estados libres. Así, antes de crear un puesto para el representante de la Santa Sede en la región, Roma firmó sendos concordatos con Costa Rica y Guatemala en 1852, Honduras y Nicaragua en 1861 y el Salvador en 1862 (Picado, 1993, 213-214).

Con estos textos ratificados por ambas partes, Roma delegó las funciones diplomáticas y de comunicación entre los obispos y la Santa Sede en delegados apostólicos, quienes en la mayoría de los casos no vivieron en Centroamérica. El primero ${ }^{4}$ de ellos fue Mons. Luigi Clementi, quien fue además delegado apostólico para México y Centroamérica entre 1851 y 1861. Él vivía en México, dejó su cargo tras ser desterrado por Benito Juárez en 1861.

El segundo fue Mons. Pietro Francesco Meglia, quien se encontraba como nuncio a la llegada de Maximiliano de Habsburgo a México, pero debido a problemas con este último a causa de las propiedades desamortizadas a la Iglesia católica mexicana fue expulsado. Trasladó la delegación apostólica a Guatemala en 1865 (Bendaña, 2011, 134). Para el 26 de octubre de 1866 fue nombrado nuncio en Alemania (http://www.catholic-hierarchy. org/bishop/bmegl.html), lo que muestra que no fungió por mucho tiempo en Guatemala.

El tercero de ellos fue Monseñor Seferino Vennutelli, a quien se le delegó el 23 de julio de 1869 el trabajo de ser el delegado apostólico en Quito. Su territorio abarcaba Colombia, Perú, Ecuador, Venezuela y las cinco repúblicas centroamericanas (Blanco, 1984, 143). Como es previsible ser encargado de tantos países y con residencias lejanas, fue sinónimo de que sus trabajos en beneficio de las naciones representadas, en especial las de América Central fueran pírricos.

El caso de Costa Rica amerita una mención aparte, debido al hecho que en 1876 fue designado como delegado apostólico Mons. Luis Bruschetti, a quien se le encomendó como principal tarea encontrar el candidato idóneo para ser nombrado segundo Obispo de Costa Rica (A. S. C. A. E. S. Costa Rica. 1865-1873. Fasc. 1. Pos. 42-43, F. 3). Bruschetti desarrolló su tarea hasta el 5 de setiembre de 1880, cuando consagró obispo del país a Mons. Thiel.

El trabajo de Bruschetti estuvo plagado de problemas con el poder civil, por el motivo de que no llenó las expectativas de Tomás Guardia, pues este último deseaba que

4. De modo "preciso" el primer nuncio para toda América del Sur y Central fue el que tuvo la nunciatura con sede en Brasil. Esta sede era la única que tenía el poder para toda esta región de América. Esta Nunciatura fue creada en 1829 por parte del Papa Pio VIII, quien delegó funciones en manos del nuncio Pietro Ostini. (Feldkamp, 2004, 73). Quien escribe no lo considera propiamente el primer nuncio para Costa Rica por dos motivos. El primero, es que quienes fueron nuncios en dicho país desde 1829 que se les confirió el título de nuncios para Centro América, nunca tramitaron, ni se presentaron ante el Estado de Costa Rica como tales mediante cartas y mucho menos de manera personal. El segundo motivo es que Roma reconoció a Costa Rica como republica libre, independiente y soberana hasta el 16 de febrero de 1850, por ende antes de esa fecha era casi imposible que existiera una representación formal y real de ambas partes (Sandí, 2012, 75). 
Bruschetti aceptara sin mayores contratiempos al candidato a obispo que el gobierno proponía, que era Isidro Cabezas. Cabezas jamás sería aceptado, por causa de la carta que recibió Bruschetti en Brasil desde la Santa Sede donde se le indicó que dicha candidatura no tenía posibilidades de éxito y que por ende debía buscar a otro más idóneo. (A. S. C. A. E. S. Costa Rica. 1865-1873. Fasc. 1. Pos. 42-43. F. 3).

Luego de concluida la tarea de Bruschetti, Roma buscó nombrar un nuevo delegado, no solo para Costa Rica, sino para toda la región centroamericana, pero el panorama político lo dificultó. En el periodo de 1882 a 1884, la Santa Sede nominó a tres hombres para que fueran delegados apostólicos en Centro América, pero por diversos motivos el plan no resultó. El primero de ellos fue Mons. José Magno nombrado en 1882 como delegado apostólico y enviado extraordinario para Costa Rica, pero no aceptó el encargo (Indice 1156 dell'Archivio Vaticano Segreto: Arch. Nuz. America Centrale; 192). En 1883 fue nombrado Mons. Spagnoletti, quien de nuevo no aceptó, (Sanabria, 2006, 144). Por último, en 1884, Roma designó como delegado apostólico y enviado extraordinario para Costa Rica a Mons. Teodoro Valfré di Bonzo, al cual se le suspendió su misión a causa de la declaratoria de las leyes "anticlericales" de 1884. A causa de esto, Roma buscaba nombrar a uno de sus representantes en estas tierras. La Santa Sede tenía conocimiento sobre el avance de las políticas liberales en la zona, por ello procuraba tener uno de sus enviados para así conseguir una posible negociación con los gobiernos liberales del área, en especial con el de Guatemala. Esta última, para la década de 1870 había declarado las leyes más fuertes contra la Iglesia católica en la región.

La expulsión de Thiel de Costa Rica y la consolidación de gobiernos liberales de línea dura en la mayoría de países del área, no impidieron que la Santa Sede siguiera con sus planes de crear un puesto donde su representante pudiera trabajar en América Central. En una comunicación cruzada entre Mons. Thiel y el secretario de Estado de la Santa Sede, Mons. Jiacobini, el primero comentó que para aquel periodo el único lugar donde se podía instaurar una Internunciatura sería Nicaragua. Thiel argumentaba que este país no perseguía a la Iglesia, pero también informó que dicha nación no lo dejó residir durante el periodo de su exilio y que por ello decidió irse para Panamá (A. S. C. A. E. S., C. R. 1884-1885. Fasc. 7. Pos. 58, F. 14). Al final no se consumó tampoco la creación de una representación diplomática de la Santa Sede en Nicaragua en la década de 1880.

Para el año de 1894 las intenciones de la Santa Sede para crear una delegación apostólica para los gobiernos de América Central y México eran muy fuertes. Llegó a tal punto que por parte de la Secretaria de Estado de la Santa Sede se le envió una carta a Mons. Thiel el 31 de marzo de dicho año preguntándole su posición con respecto a que Costa Rica fuera la sede. La respuesta de Thiel fue un extenso análisis en latín ${ }^{5}$ de la situación económica, política, militar, geográfica, climática y social tanto de Costa Rica como de México, Guatemala, Honduras, El Salvador y Nicaragua. Thiel expuso que Costa Rica se encontraba en el punto más meridional del Istmo centroamericano, colindando con Colombia (Panamá), donde existía un nuncio en Bogotá. El clima rondaba como mínimo

5. Las citas que se utilizarán sobre este informe de Mons. Thiel, así como otro texto que indica que su original estaban en latín fueron traducidos al español por el Pbro. Luis Diego Sáenz Salazar y el autor. 
en el Valle Central los $12^{\circ}$ y lo máximo $22^{\circ} \mathrm{C}$, con una altitud de 3900 pies sobre el nivel del mar, 250000 habitantes en todo el país, de los cuales casi todos católicos y que en la capital donde debería ser colocada la delegación habían 20000 habitantes. Sobre el gobierno del país, Thiel argumentó:

El gobierno actual ni persigue a la Iglesia ni la favorece mucho. (El subrayado es propio del texto original) Comparado con los Gobiernos de México, Guatemala, El Salvador y el de Honduras el gobierno de Costa Rica es magnífico. José Joaquín Rodríguez presidente de la República asiste todos los días domingo al sacrificio de la misa en la Iglesia Catedral acompañado por la tropa. (A. S. C. A. E. S., C. R. 1892. 1893. Fasc. 18. Pos. 76-81. Ff. 69-74.)

Además de lo expuesto anteriormente, Thiel mencionaba que Costa Rica tenía otras ventajas, como lo eran la buena comunicación con el resto de repúblicas hasta México, gracias al telégrafo que por comunicado cobraba 12 francos. Al mismo tiempo argumentaba que la comunicación mediante cartas era expedita, ya que en menos de 7 días, gracias a los vapores se podía enviar cartas a México, vía Nueva Orleans y Nueva York, lo que permitía tener una respuesta de una primera carta en menos de dos semanas. El mismo argumento utilizó para explicar la comunicación por el Océano Pacífico para el resto de repúblicas centroamericanas.

Mons. Thiel reconoció la urgencia de instalar una delegación apostólica en el área, pues por más de 30 años México y las repúblicas de América Central vivían "separadas" de la Santa Sede. Para Thiel, esta premura era a causa de que casi la totalidad de habitantes de dichos países eran buenos católicos. De igual manera el obispo refiere el carácter de urgencia debido a las políticas liberales implementadas en la región y que cortaban la libertad de los fieles de cada país. Además, mencionaba que el nuncio más cercano era el de Bogotá, el cual por distancia no hacía mucho a favor de la zona. Por último, indicaba que de todas estas repúblicas por el "momento Costa Rica ofrece seguridad relativa" en el establecimiento de la posible delegación, gracias a que el propio presidente de la república le había dicho que: "siempre sería bien recibido un enviado de la Santa Sede".

Thiel trató de ser lo más objetivo posible en su repuesta, por ello mencionó los puntos en contra que podía tener Costa Rica como sede. El primero era que por las leyes liberales de 1884 se había derogado el Concordato firmado en 1852 y que en el Congreso Nacional existían algunos liberales, pero que no eran "tan hostiles para con la Iglesia". Unido a esto Thiel mencionaba que era una república muy pequeña al punto que ningún gobierno:

del mundo tiene en Costa Rica representante diplomático de carrera, a no ser Francia que nombra vice-Cónsules. Los demás gobiernos de mundo tienen agentes consulares, quienes son llamados cónsules. Por lo común son comerciantes. Las representaciones diplomáticas para toda América Central residen en Guatemala. Allá Francia, Gran Bretaña, Alemania, Italia y los Estados Unidos tiene a su ministro general. (A. S. C. A. E. S., C. R. 1892.1893, Fasc. 18. Pos. 76-81. Ff. 69-74)

La pequeñez del país para Thiel se reafirmaba con el hecho de que solo tenía dos diplomáticos en el mundo, uno para Estados Unidos y otro para "los gobiernos de Europa, que ordinariamente reside en París o en Madrid". Unido a esta pequeñez, Thiel 
mencionaba que la vida en el país era dispendiosa, que solo por alimento y alquiler de la casa, sin tomar en cuenta el posible salario del secretario y los muebles de la casa, el delegado pagaría unos 750 francos de la época. Por lo demás, mencionaba que seguridad absoluta de paz no existía ni en Costa Rica ni en ninguna parte de la región. Para Thiel el principal problema era que si el nuncio tomaba como residencia Costa Rica estaría solo, por el hecho de que el resto de diplomáticos residían en Guatemala y en Costa Rica solo había agentes consulares, quienes en su mayoría eran comerciantes.

Este dato de la escasa repercusión que tenía Costa Rica en el concierto diplomático internacional es de suma importancia, debido a que el representante del Papa que se enviara debía estar ubicado en un lugar donde sus acciones tuvieran eco, y Costa Rica en aquel momento no tenía esa relevancia. Enviar un delegado apostólico no era por la simple razón de tener buenas relaciones con los países del área, era demostrar que aún la Santa Sede en medio del proceso de secularización llevado acabo con altibajos en las repúblicas de la región tenía alguna injerencia política. Thiel era conocedor de esto, y buscaba que la mediación del enviado papal fuera fundamental en el proceso de romanización del clero, donde el Papa debía de representar una figura de poder, ya no militar, pero sí de prestigio mundial y si era el caso de intermediario en disputas entre países.

Thiel concluía su informe aconsejando a Roma qué era lo mejor por hacer. Para ello mencionaba que había dos opciones, la primera era crear la delegación en Costa Rica por un tiempo y en dicho lapso el enviado en persona observase por sí mismo la verdad de las circunstancias y así informara a la Santa Sede con mayor certeza lo que convendría hacer. La segunda opción era crear una delegación apostólica en la ciudad de Washington, Estados Unidos, para que fuera el delegado de toda la zona hasta Costa Rica. Thiel defendía esta hipótesis argumentando que la comunicación entre todas las capitales con la de los Estados Unidos era fluida y constante. Además, dijo que "todos los gobiernos de América Central y México tienen en la ciudad de Washington sus mejores diplomáticos".

Esta propuesta de Thiel sin duda alguna corrobora la hipótesis de que el nuncio debía estar en un lugar de peso político, por ello recomendó la capital de los Estados Unidos. A final de cuentas, esta información no deparó en la escogencia de Costa Rica, ni de ningún país de la región como sede de la delegación apostólica.

Fue hasta 1908 que Roma tomó la determinación de crear para América Central una delegación apostólica en Costa Rica. En ese año y luego de analizar otra carta enviada por Thiel en 1900, la Santa Sede le solicita al sacerdote costarricense Antonio del Carmen Monestel que le pregunte al Presidente de la República si aún estaría dispuesto a aceptar un enviado pontifico al país, a lo cual don Cleto González Víquez, Presidente de la República en aquel momento, respondió de manera afirmativa.

Esta respuesta fue sustentada gracias al modo como Monestel le presentó el panorama a González Víquez al indicarle que la aceptación de la delegación sería un apoyo por parte de Roma a Costa Rica, por la razón de que era el país en el cual la Santa Sede confiaba por su ambiente de paz y tranquilidad política, militar y social para establecer la casa para su representante. De igual manera, Monestel hizo ver al presidente que esta aceptación: "haría inspirar mas [sic] confianza a los Gobiernos extranjeros quienes procurarían acreditar sus Ministros ante el nuestro con residencia en nuestro país y 
todo esto redundaría en bien de la Nación." Sin duda alguna, esta afirmación caló en el presidente, quien aceptó el nombramiento. (A.S.V.: A. N. A. C. Fasc. 32. Diocesi di San Jose Ff. 73-75.)

Esa aceptación confirma lo que los liberales querían demostrar de este país en aquel momento, en el cual el orden y el progreso que tanto pregonaban era una realidad. Este orden y progreso no era para todos, pero en comparación con el resto de países del área, Costa Rica se encontraba "mejor", a causa de que técnicamente tenía una democracia "competitiva", donde cada cuatro años había elecciones para la escogencia "libre y democráticamente" de sus gobernantes y que desde 1870 no se daba un golpe de Estado. Como es conocido esta competitividad electoral y la escogencia libre y democrática de los gobiernos en Costa Rica no era del todo cierta. Por ejemplo, Tomás Guardia gobernó por defacto desde 1877 hasta 1882 año en el que murió; en las elecciones en las cuales salieron victoriosos Próspero Fernández y Bernardo Soto técnicamente solo ellos fueron los candidatos. Para la elección de 1889, si no hubiese sido por el levantamiento del 7 de noviembre se hubiera impuesto en el poder el candidato perdedor Ascensión Esquivel, el cual era apoyado por el gobierno de turno (Molina, 1989; 184-185). De igual manera se dio fraude en contra del Partido Unión Católica en 1894 (Sánchez,2013; 200), la segunda elección de Rafael Yglesias en 1902 fue realizada mediante componendas políticas no del todo claras y permitidas (Calvo, 1980, 97-111) y por último, las elecciones de 1902 y 1906 también estuvieron salpicadas por el fraude (Salazar, 2003)

Estos actos no muy democráticos fueron muy bien "invisibilizados" por la estabilidad política que representaba Costa Rica a nivel internacional. Dada esta realidad la jerarquía católica con residencia en Roma escogió al país como la sede del delegado apostólico para el área. Un elemento a considerar es que Costa Rica, a diferencia de los otros países de la zona, no expulsaba a su obispo desde 1884, y la relación luego de 1886 entre Thiel y Stork con el Estado fue relativamente cordial. Esto no quiere decir que no hubo discrepancias, pero ninguna desembocó en una nueva expulsión o en una situación realmente tensa que comprometiera la relación entre ambas instituciones, hecho que a la Santa Sede le fue suficiente para designarla como sede de la delegación apostólica.

Para inicios de 1908, la Santa Sede por orden del papa Pio X creó la delegación apostólica para las repúblicas de Costa Rica, Honduras y Nicaragua (estas por confirmarse) con sede en San José, y nominó el 10 de junio del mismo año como delegado apostólico a Mons. Giovanni Cagliero, arzobispo titular de Sabeste. Con él, iniciaron realmente las relaciones diplomáticas directas y efectivas entre parte del istmo y la Santa Sede.

El siguiente punto a desarrollar serán las instrucciones que de modo general les indicaron a los encargados de representar a la Santa Sede en la región, que en la mayoría de las ocasiones fueron las mismas para todos.

\section{Las tareas a desarrollar por los representantes de la Santa Sede en América Central entre 1908-1936}

Las instrucciones generales que de Roma se giraron a los delegados apostólicos, internuncios y nuncios de la región para contrarrestar las consecuencias del liberalismo, acrecentar el proceso de romanización del clero y fortalecer las relaciones diplomáticas 
entre ambas partes fueron principalmente nueve: 1) Buscar la reorganización de la vida religiosa católica en las repúblicas del área. 2) Tratar de establecer la comunión de pensamiento de todos los prelados de la región. 3) Incentivar que los obispos pusieran en práctica lo establecido en el Concilio Plenario Latinoamericano, que tuvo lugar en Roma en el año de 1899 (consolidación de la romanización del clero). 4) Procurar que el laicado participara más de lleno en la vida activa de la fe, en especial en organizaciones de índole social. 5) Se le solicitaba a los enviados papales propiciar por todos los medios ser reconocidos por las cinco repúblicas como los diplomáticos designados por la Santa Sede en los países del área. 6) Buscar por todos los medios derogar las leyes de corte anticlerical que se decretaron en la región luego de 1870, en especial la de la educación laica. 7) Se les solicitaba a los representes del Obispo de Roma ser los "certificadores" de las noticias ("buenas y malas") que llegaban a Roma, sobre prelados, sacerdotes, fieles y gobernantes. 8) Realizar descripciones detalladas sobre la situación política, religiosa, social, económica, cultural y militar de los países de la zona. 9) Analizar cuál era el verdadero estado de infiltración tanto en la sociedad, como en la cúpula gobernante y el propio clero de la masonería y el protestantismo llegado desde los Estado Unidos. ${ }^{6}$

Estas indicaciones perseguían ciertos objetivos fundamentales para la Santa Sede. Estos eran: 1) los informes le permitían a Roma conocer la realidad política social, económica, militar y cultural del país, 2) buscar y dar las mejor indicaciones y medios para mejoramiento de la catequización sobre los fieles de cada país, 3) fortalecer el proceso de romanización del clero autóctono, y 4) luchar contra la secularización de la sociedad, la influencia de sociedades secretas y del protestantismo en el área.

\section{Las tareas de los representantes del Papa en América Central entre 1908 y 1936}

Una de las principales tareas solicitadas por Roma a todos los enviados era establecer (si no lo había) o consolidar las relaciones diplomáticas entre la Santa Sede y las naciones del área. Cuando Mons. Giovanni Cagliero arribó a Costa Rica su nombramiento establecía que sería el delegado apostólico para el gobierno de dicho país, pero se le solicitaba que procurase ser reconocido por todas las repúblicas del área tarea que consiguió a medias, debido a que nunca fue reconocido como tal por parte de Guatemala y El Salvador.

Para lograr el cometido solicitado por Roma, Mons. Cagliero se valió de una estrategia diplomática para conseguirlo. Él había llegado a Costa Rica el 8 de agosto de 1908, dos días después le envió una documentación a Mons. Stork, Obispo de Costa Rica, en la cual le indicaba que enviara la carta adjunta, pero con la firma de Stork y no de Cagliero

6. Estas directrices fueron extraídas de los archivos Vaticanos, ya que en el "Archivio degli Affari Steri" (en este archivo por ejemplo en el Fasc. 29 Posizione 100" se encuentras las instrucciones para Mons. Giovanni Cagliero y en el Fasc 30, Posizione 105 las de Mons, Giovanni Mareno) y "Archivio Segreto Vaticano" (por ejemplo en la caja:Fasc.17 Segretaria di Stato (Arch. Nuz. America Centrale) están las de Mons. Angelo Rotta, y en Fasc. 84. Governo di Costa Rica (Arch. Nuz. America Centrale) las de Mons, Carlo Chiaro). se encuentran las instrucciones para cada uno de los representantes enviados. 
a los presidentes de Nicaragua y Honduras. La carta tenía como tema principal exponer a los presidentes de dichas naciones la siguiente situación:

Tengo en mi Palacio al Excelentísimo Señor Delegado Apostólico, acreditado ante el Gobierno de Costa Rica como Ministro Extraordinario y encargado de los asuntos religiosos de la Iglesia Católica en Centro América.

Se comprende que el Excelentísimo Señor Delegado tiene el deseo de tener una idea exactísima del estado de la Iglesia en las diferentes Repúblicas Centroamericanas, para tomar sus providencias en bien de los pueblos y de las relaciones con los Gobiernos, para evitar ciertas dificultades que por motivos que no quiero examinar se ha presentado en los últimos tiempos.

Por esto me permito preguntarle a Su Excelencia, para poder aconsejar al Señor Delegado, si cree conveniente una visita de dicho Prelado a la República de Nicaragua [u Honduras en su defecto], para examinar las cuestiones disciplinarias, eclesiásticas y facilitar la armonía entre el Clero y el Gobierno. (A.S.V.: A. N. A. C. Fasc. 95 Corrispondenza con i governi dell'America Centrale. Ff. 2-3)

Nada de lo escrito fueron ideas o palabras de Stork, todo fue ideado por Cagliero. Esto se puede corroborar porque en la fuente consultada el mismo Cagliero lo indicó, además la carta está en su libro copiador, donde se mostraba que fue él quien la planeó. ¿Cuál era el verdadero interés de Cagliero y de Roma en establecer relaciones con estas pequeñas y recónditas repúblicas, como eran llamadas por ellos mismos? Esto lo explica la otra acción que se desarrolló luego de la respuesta de los presidentes José Santos Zelaya de Nicaragua y Miguel R. Dávila de Honduras. Los dos, sin conocer que no era Stork quien solicitaba el permiso sino el mismo Cagliero, respondieron afirmativamente a la solicitud del Obispo de Costa Rica, indicando que el delegado podía llegar cuando él quisiese.

Luego de esto, Mons. Cagliero hizo su jugada en el ajedrez diplomático. Se presentó como el representante del Papa y que estaba esperando la llegada de las credenciales para presentarse ante ellos. Además se mostró como el personaje idóneo para intermediar, bajo el cargo de representante del Sumo Pontífice, en el conflicto que en 1908 se dirimía en la Corte de Justicia Centroamericana entre los gobiernos de Honduras, Guatemala y El Salvador el cual era de origen militar y fronterizo.

Esta acción evidenció uno de los verdaderos intereses de la Santa Sede en entablar relaciones diplomáticas con estos países. Es imposible obviar que el interés evangelizador y catequético existiera, ya que este fue, es y será (al menos debería de serlo) una cuestión constante en todos los movimientos que se decretaron desde Roma. No se puede ocultar la intención por parte de la Santa Sede de seguir siendo una institución de peso político internacional, que buscaba mediante su intermediación la paz, o al menos acuerdo en términos "amistosos" a través del accionar del representante del Papa entre los países litigantes.

Esto lo demostró la inquietud de Cagliero de ser intermediador en el conflicto. Al final no consiguió serlo, a causa de la respuesta con la cual se manifestó el presidente de Nicaragua: "creo no deben aceptar la mediación propuesta por V. E., porque este es el primer ensayo que hace la Corte de Cartago y se quiere ver qué importancia práctica puede tener ese Alto Tribunal en las cuestiones políticas Centroamericanas", (A.S.V.: A. 
N. A. C. Fasc. 85 Governo di Nicaragua. Ff. 55-57), pero sí fue una muestra clara del por qué Roma enviaba entre otros fines a uno de sus representantes a estas tierras.

Otro de los datos a tomar en consideración de esta participación de Cagliero en la resolución del problema entre las naciones centroamericanas es el origen de la Corte de Justicia Centroamericana. Esta corte nació del acuerdo denominado Conferencia de la Paz de Washington. En el cual los países centroamericanos se comprometían a resolver cualquier disputa de la naturaleza que fuese, mediante dicha corte. Roma tenía cierto temor de la influencia que estaba ejerciendo los Estados Unidos sobre la región.

El miedo era ocasionado por ser una gran potencia, pero de credo protestante. Por ende, la Santa Sede buscaba la manera de hacerse también presente para demostrar su papel diplomático y con ello evitar la influencia de los protestantes y un posible mayor avance de esta doctrina cristiana dentro de las sociedades católicas de América Central. Esto quedó demostrado cuando a los propios enviados papales se les solicitaba realizar informes no solo sobre la masonería y el protestantismo, sino de cómo los Estados Unidos influían para que estos dos elementos crecieran en la región.

En 1923 se daba una contienda electoral en Costa Rica de las más reñidas de su historia. Para aquel periodo el internuncio era Mons. Angelo Rotta; de igual manera, en aquel año hubo elecciones presidenciales en Honduras. Como Roma lo solicitaba, el internuncio envió varios informes minuciosos sobre el desarrollo de estas contiendas políticas. Se analizará el caso de Costa Rica por ser el más detallado y el más representativo de los dos.

Los contendientes electorales para el caso costarricense eran Ricardo Jiménez, por el Partido Republicano, el ex sacerdote Jorge Volio, por el Partido Reformista y Alberto Echandi, por el Partido Agrícola. Esta elección llamaba la atención de la Santa Sede debido a ciertos factores que merecían un análisis cuidadoso. Además de estar Jiménez Oreamuno como candidato, quien era conocido por su liberalismo, se encontraba el hecho que el principal oponente a este era un ex-cura que le había ocasionado varios "problemas" a la jerarquía católica costarricense, como a la misma Roma desde inicios del siglo XX. Por ser Jorge Volio el candidato, el informe realizado por Rotta fue más detallado.

La preocupación más relevante para Mons. Rotta eran las relaciones diplomáticas entre Roma y Costa Rica dependiendo del resultado electoral. A causa de esto, indicó que si ganaba Echandi las relaciones se mantendrían como siempre. Si la victoria era del Partido Republicano la situación podría ser la misma, ya que Jiménez había sido presidente entre 1910-1914, tiempo durante el cual Cagliero fue el delegado apostólico y la relación se mantuvo en armonía. El problema, según Rotta, se fundamentaba en que si Volio obtenía la victoria, no se podría saber a ciencia cierta lo que podría acontecer, debido a que el Partido Reformista, junto al propio Volio, era de "tendencia socialistoide."

Ante este panorama Rotta presenta su opinión al respecto y dijo?:

7. Todas las citas utilizadas de los informes de los representantes papales estaban escritas en italiano y fueron traducidas al español por el autor. Por ende, todo lo que sean citas de Mons. Rotta e Mons. Chiarlo su original eran en italiano. 
Se debiera hacer una elección entre las personas, cierto que la haría: Echandi, puede ser un creyente no practicante,... pero es una persona recta de buena conducta moral, mientras que el abogado Jiménez no solo no es practicante, sino que también vive en concubinato; y el así llamado General Jorge Volio es un ex sacerdote.

Sobre Volio el Internuncio le dedicaba más líneas y mencionaba que:

Realizó sus estudios eclesiásticos en Lovaina [Bélgica], donde fue consagrado sacerdote y se llenó la cabeza y el espíritu con el modernismo. Regresó a la patria donde ejerció solo por algunos años el ministerio sacerdotal, luego se convirtió en jefe de una facción armada que ayudada por los liberales de Nicaragua procuraban una revolución contra el Presidente de Costa Rica [Federico Tinoco]... De esta acción es que se le dio el nombre de General que ahora tiene. Fue amonestado una vez por irregularidad...

Cierto sería que su llegada a la presidencia metería en un serio problema a la Iglesia de Costa Rica y al Representante Pontificio: pero por lo que se puede ver no hay posibilidades para él por el momento... (A. S. V.: A. N. A. C. Fasc. 17 Segretaria di Stato. Ff. 16-19v)

El 6 de diciembre de 1923, Mons. Rotta escribió una carta a la Secretaria de Estado de la Santa Sede mediante la cual comunicaba que las elecciones tuvieron el siguiente resultado: Ricardo Jiménez del Partido Republicano 29.839 votos, Alberto Echandi, del Partido Agrícola 26.244 y Jorge Volio del Partido Reformista 14.102 votos (A. S. V.: A. N. A. C. Fasc.17 Segretaria di Stato. Ff. 93-94). Unido a esta información Rotta mencionaba que ninguno de los candidatos había obtenido los votos suficientes para ser Presidente de la República y por ende se debían dar acuerdos políticos para sacar a un vencedor en el Congreso. A causa de esto, volvió a escribir a Roma dando una descripción más detallada de los candidatos.

A Echandi lo siguió considerando un no practicante, sí una persona educada, respetuosa, que no le ocasionaría problemas a la Iglesia y que aunque no era el más idóneo por su falta de energía para gobernar era mejor que Jiménez y Volio. A Jiménez mientras tanto, lo terminó de catalogar como:

... ya había sido Presidente de la República, goza por esto de prestigio personal; es un hombre con ingenio, buen orador, tiene muchos amigos. Desgraciadamente es un incrédulo, un volteriano, un teórico del liberalismo, un inmoral, porque convive con una mujer sin ningún vínculo.

El elemento masónico teosófico para él es natural y lo favorece. Y esto lo hace notorio contra católicos, él es un entusiasta secularizador, pero aún así hay sacerdotes que se declararon jimenistas, todo esto lo hace el peor de todo, además ha realizado discurso contra las congregaciones religiosas hace un mes en el Congreso. Carece de conciencia religiosa profunda, así como de sensibilidad moral. El señor Jiménez con los suyos, conducen la campaña de un modo altivo enérgico.

Sobre Volio y el propio clero costarricense el enojo de Rotta era mayor y decía:

Entre otras cosas relevantes que se ha dado en esta lucha es el número impresionante de votos que reportó el desgraciado ex sacerdote Jorge Volio. Y debe de ser tomada en serio la propaganda insidiosa y audaz hecha por él y sus secuaces y con una actividad envidiable, de principios socialistoides [sic], dirigida a la parte más baja del pueblo, también usó un discurso anticlerical, bajo la norma de la lucha por el clero como aliado natural del patrón... además ha indicado en todos los rincones de la República que él se propone continuar con esta lucha luego de la contienda electoral. 
¿Y el clero? El clero dio un ejemplo desalentador de la desunión y del defecto en varios de ellos del sensun Christi, que debe ser la norma suprema de la política. Aquí el voto es público, y entonces se sabe por cuál de los candidatos se votó: de los seis miembros del capítulo, tres votaron por Jimenez! [sic]de igual manera dos o tres párrocos; algunos votaron por Volio e incluso un sacerdote, no uno de los mejores, figuraba en la papeleta de candidatos a la Diputación por el partido reformista! Dos sacerdotes fueron elegidos a diputados por el partido agrícola. (A. S. V.: A. N. A. C. Fasc. 17 Segretaria di Stato. Ff. 93-94).

Poco tiempo después, Mons. Rotta comunicó a Roma que el vencedor de las elecciones en Costa Rica había sido Ricardo Jiménez. El internuncio, como decano del cuerpo diplomático, tuvo que dar un discurso el 8 de mayo de 1924, día de la toma de posesión de Jiménez, a quien catalogó como el hombre idóneo y propicio para guiar los destinos de Costa Rica durante los futuros cuatro años. ¿Cómo se debe entender este proceder del internuncio?, ya que meses antes lo había catalogado de indigno y le recalcaba estar amancebado con una mujer que había sido prostituta ${ }^{8}$ (Saénz, 2001, 535-543). ¿Era un doble discurso por parte del internuncio lo dicho en este día? La respuesta es que él había sido enviado para ser embajador en Costa Rica, no tribunal de las decisiones que tomara el pueblo y el gobierno.

Rotta dio su parecer tal cual se lo pedía Roma, pero en el momento en que los hechos se dieran, fueran de su agrado o no, él debía aceptarlos y si era del caso mostrarse complacido. Esto porque a todos los enviados de la Santa Sede siempre les pidió conservar y acrecentar las relaciones diplomáticas con los países. Por ende, si Rotta dijo que Jiménez debía de ser el indicado fue porque lo tuvo que decir, sintiera o no lo que decía, ya que su papel además de ser informante de Roma era el de conservar las relaciones entre Roma y Costa Rica en este caso.

Los informes enviados por parte de Mons. Rotta a causa de estas lecciones presidenciales de 1923 en Costa Rica son clara muestra, así como elemento probatorio de los conceptos acá utilizados. Por un lado, estaba la preocupación constante de que llegara un liberal al poder y que así se continuara con la idea de secularizar toda la sociedad, situación que nunca sucedió en Costa Rica. Por otro lado, estaba la intención de reforzar y consolidar la romanización del clero porque la participación en política de un ex-cura, de otros sacerdotes y la desunión que estos mostraban era sinónimo de una fractura en el clero costarricense.

8. Como dato curioso se puede mencionar que el matrimonio entre Ricardo Jiménez y Beatriz Zamora López lo realizó monseñor Giuseppe Fietta Internuncio con residencia en Costa Rica. Se copia in extenso una descripción sobre este hecho:

Italiano cultísimo (Mons. Fietta) figura ascética sacada de un cuadro del Greco, fino diplomático que jamás colocó una tuerca en el delicado mecanismo de sus asuntos sin antes aceitar con sumo cuidado la rosca y el tornillo, inició con tacto florentino y sabiduría jesuita, los sondeos tendiente a conseguir que don Ricardo y doña Beatriz se casaran por la iglesia y, naturalmente, inició sus delicadas gestiones a la señora. Liberal auténtico y por lo tanto tolerante en cuestiones religiosas, agnóstico declarado y convencido, don Ricardo le hizo a la mujer amada la concesión de pasar por esa formalidad que siempre respetó por ser fundamental de la familia, la sociedad y la nación, formalizando así a los ojos del mundo, una unión feliz de muchos años. No tenía hijos y ya estaban viejos cuando se efectuó el matrimonio, en forma muy privada, oficiado por el Nuncio de Santidad el 21 de diciembre de 1928; don Ricardo tenía 69 años y doña Beatriz 57. (Saénz, 2001, 539). 
Este último elemento, sin duda alguna era, de suma importancia para Mons. Rotta, debido a que él veía en la romanización del clero la medicina propicia para este "mal". Además, pensaba que si todos se unían bajo los designios y poder absoluto del Papa no se presentarían estas divisiones dentro del clero. Por lo tanto, y como ya se ha dicho, es imprescindible tener claro los procesos de secularización, laicización y romanización del clero para comprender el accionar de los enviados papales.

Todos los representantes pontificios (que fueron en el periodo acá estudiado: Mons. Cagliero (1908-1915), Mons. Marenco (1917-1922), Mons. Rotta (1922-1925), Mons. Fietta (1926-1930), Mons. Chiarlo (1932-1940)) tenían la obligación de enviar informes de índole religioso sobre todos los países del área. Se puede decir que al menos se entregó un informe sobre el estado religioso de cada nación por parte de cada enviado a la Santa Sede.

Para citar ejemplos de ello, se puede mencionar que la división dada de la diócesis de Costa Rica en 1920, en la cual se crearon la arquidiócesis de San José, la diócesis de Alajuela y el vicariato Apostólico de Limón, se dio por los informes realizados por Mons. Cagliero y Mons. Marenco. Esto debido a que la división planeada por Mons. Stork, obispo de Costa Rica buscaba crear la arquidiócesis en San José y dos vicariatos apostólicos; uno en Puntarenas, atendido por los Dominicos; y otro en Limón pastoreado, por los Paulinos (A. S. V.: A. N. A. C. Fasc.25 Congregazione Concistoriale. Ff. 59-64).

Esta división no se consolidó debido a los informes religiosos, políticos, demográficos y económicos realizados por Cagliero y Marenco. Esto es muestra inequívoca del poder que portaban estos hombres sobre el episcopado regional. Poder que solo se explicaba bajo la autoridad que tenía el Papa, quien para el bien de su Iglesia lo podía delegar en estos sujetos de su confianza, que le informaban sobre los estados reales de las cosas en cada país.

El acatamiento de los prelados de América Central a las órdenes y disposiciones de los delegados papales se explica sólo si se comprende la unión y obediencia de los obispos con el Papa. Las decisiones debían ser ejecutadas por sus representantes dada su autoridad divina.

En 1926 el Internuncio Mons. Guiseppe Fietta le envió al Secretario de Estado de la Santa Sede, el cardenal Mons. Pietro Gasparri, un minucioso informe sobre la coronación de la Virgen de los Ángeles en Costa Rica, donde dijo:

Soberbio el espectáculo..., imponente la Misa Pontifical celebrada por el Mons. Arzobispo [Rafael Otón Castro] en presencia del Presidente que tomó lugar en el trono preparado para él, unido a las autoridades eclesiásticas y civiles y una inmensa cantidad de personas que se había reunido en torno, la iglesia artísticamente adornada, pero sobretodo inolvidable los instantes solemnes en los cuales Mons. Arzobispo, para tal propósito delegado del Venerable Cabildo de San Pedro [Roma], impuso sobre la cabeza de la Virgen la Corona, mientras se daba en el más absoluto silencio de las 50.000 personas que asistieron a la amplia plaza, 5 bandas [musicales] entonaban contemporáneamente el himno nacional [de Costa Rica], esto como solemne muestra de la fe de toda la Nación para su Patrona. 
Para Mons. Fietta era importante mencionar esto, a causa de que lo sucedió aquel 25 de abril de 1926. Para él era una muestra no solo de la fe de un pueblo hacia su patrona, sino también de unión y armonía entre el poder civil y eclesial. Esto último, sin duda alguna era bien visto por Roma, pues su constante directriz de buscar la concordia entre ambas instituciones era primordial. Por ende, este informe unió lo religioso y lo político, asunto que era de relevancia para la Santa Sede y del cual anhelaba leer.

En estos informes no solo se enviaba documentación que se pudiera denominar beneficiosa para la Iglesia, sino era tarea de los representantes papales informar a Roma del mal proceder de obispos o sacerdotes. Tal fue el caso del cura Joaquín Villaplana, quien vivía en Costa Rica en 1926. Él fue suspendido por Mons. Castro, primer Arzobispo de San José. Esta decisión fue aceptada por Roma gracias a las informaciones enviadas con anterioridad por Mons. Rotta, quien en comunión con el obispo Castro, dejaban claro que el cura Villaplana era un sacerdote muy lejano al verdadero comportamiento que debía tener uno de ellos. Estas aclaraciones se dieron gracias a su carácter violento, además nunca usaba sotana, no iba a misa ni en los días de precepto, no frecuentaba los sacramentos, además hablaba mal de la jerarquía católica y nunca mostró sentimiento de reivindicación o arrepentimiento por su comportamiento. (A. S. V.: A. N. A. C. Fasc.28 Congregazione Concistoriale. F. 69). Para concluir, en el Fascículo 17 del Archivo Vaticano Secreto, de la sección Archivio della Nunziatura dell' America Centrale, se encuentran todos los informes realizados por Mons. Rotta sobre todos los países del área, él se dio a la tarea de visitar cada uno de ellos, no solo para presentarse como representante del Papa, sino para conocer en persona lo que en cada nación sucedía.

Por último, en esta sección se analizará cómo fue establecido el poder que poseían estos representantes, aunque no solo lo decretado en el Derecho Canónigo de 1917 fue lo que reguló las tareas realizadas por ellos. El 6 de mayo de 1919, por decreto de la Sagrada Comisión Consistorial, se publicó un documento en latín, el cual se hizo llegar a todos los representantes papales dispersos por el mundo. Este texto dejaba en claro los casos en los cuales el representante papal podía decretar, disponer y juzgar sin solicitar permisos a Roma. Esto se dio a causa de los problemas de comunicación, por las distancias que existían entre la Santa Sede y sus diferentes delegados. El texto es bastante extenso, por lo que solo se expondrán los puntos más importantes.

En las condiciones generales se les indicaba a los enviados ser los encargados de hacer visitas a las zonas de su jurisprudencia diplomática para verificar el estado real de las diócesis y países, realizar minuciosos informes de las personas presentadas para ser nombradas obispos, así como dispensar a sacerdotes para ofrecer el sacramento de la eucaristía. De igual manera, debían eximir por causa justa de algún juramento, siempre y cuando no se perjudicara a un tercero.

En el caso de las indulgencias, se le concedía al enviado papal el derecho de concederlas seis veces al año por motivos de solemnidades. También podía impartir la bendición papal tres veces al año, pero no en el mismo sitio. De igual manera, podía conceder la indulgencia plenaria a aquellos que se convirtieran de la herejía y volvieran al seno de la Iglesia católica en el momento de su conversión. Además, podía erigir las estaciones del Via Crucis con aplicación de indulgencias, igualmente la Pía Hermandad del Santo Rosario, de la Bienaventuradas Virgen del Monte Carmelo y la Virgen de los 7 Dolores. 
Este poder tenía un valor agregado, el cual era presentar la figura del Papa como una persona realmente cercana a los fieles, pues muchos en su vida nunca lograron ver ni un cuadro, fotografía o en persona al sucesor de Pedro, pero sí tuvieron su bendición e indulgencias gracias al trabajo de sus representantes. Este poder de bendecir e indultar en nombre del Papa se explica solo si se comprende la unión de todos los obispos con el Obispo de Roma, lazo que estrechó en mayor medida la romanización del clero.

Respecto al matrimonio y a otros sacramentos el representante papal podía: dispensar hasta 50 veces por causa grave de todos los impedimentos dirimentes del matrimonio, ya fueran por derecho eclesiástico, por derecho público o que estuvieran ocultas. Además, sanar in radice por 25 veces los matrimonios nulos por causa de impedimentos dirimentes. Sobre la eucaristía, podían conceder el indulto de celebrar fuera de iglesia u oratorio público en casos particulares, además de erigir altar a cielo abierto.

Respecto a los religiosos tenían derecho por ejemplo a permitir que las monjas en caso de enfermedad, o por algunas causas graves, pudieran vivir fuera del claustro por un tiempo. También podían dispensar a los religiosos de ambos sexos, únicamente por razones de conciencia, salir de la congregación y permitir que volvieran al mundo, siempre y cuando estos hubiesen obtenido la declaración de nulidad de sus votos por invalidez.

Por último, los propios representantes tenían otras facultades para ellos mismos. Por ejemplo, podían y debían: recitar el oficio divino y de celebrar la Santa Misa según el Calendario Romano, conservar en una capilla de su residencia estable el Santísimo Sacramento, administrar el Sacramento de la Confirmación, apoyándose en su derecho de jurisdicción universal, lo mismo que durante un viaje marítimo cuando iba a tomar posesión o cuando regresaba del lugar de su misión. De igual manera, recibir la confesión sacramental de los fieles de ambos sexos, en el lugar de su jurisdicción o en un viaje marítimo. Por último, poder lucrar para sí mismo las indulgencias que por su oficio se le habían concedido para impartirlas a los demás. (A. S. V.: A. N. A. C. Fasc. 1. Ff 49-53).

Con todo esto el representante del Papa era visto, sin serlo necesariamente, por el propio clero y los feligreses como el jefe del o los obispos de la zona que estaban bajo su jurisdicción diplomática. Por esto, no es extraño encontrar en la correspondencia recibida por ellos cartas de sacerdotes y fieles pidiendo su intervención para "sanar" un hecho del cual el obispo era culpable o había tomado medidas que el remitente de la carta no le agradaban.

Esto se convirtió en un serio problema entre los representantes papales y los obispos, ya que en muchas ocasiones el enviado de Roma terminó metiéndose en el campo de acción de los obispos, como ocurrió en varias ocasiones. Para el caso de Costa Ricaun ejemplo de ello fue cuando Mons. Stork fue obispo del país y los enviados de la Santa Sede fueron Mons. Cagliero y Mons. Marenco, estos últimos impusieron sus criterios para el modo en cómo fue dividida la Diócesis de Costa Rica en 1921, esto por encima de la propuesta presentada por Stork a Roma. Este accionar se dio a causa del mayor grado de confianza que la Santa Sede tenía en sus enviados. 


\section{Conclusiones}

La designación de Costa Rica como sede para residencia del representante del Papa en la región respondió al grado de estabilidad política que este país mostró a la comunidad internacional. Unido a esto, se adjuntaba el elemento de que los liberales que gobernaron eran menos beligerantes que en el resto de América Central, lo cual fue fundamental para que la Santa Sede tomara dicha determinación.

La decisión de que San José fuera la sede no respondió a hechos religiosos, sino más bien políticos, sociales, económicos, militares y de medios y vías de comunicación. Tal como lo indican los informes de los diferentes enviados pontificios la religiosidad en el resto de países del área era mayor a la de Costa Rica, pero esta nación ofrecía la tranquilidad que necesitaba un diplomático para trabajar, debido a que el resto de países de la zona presentaba golpes de Estado y expulsiones de los obispos, lo cual los volvían inestables para los intereses de Roma.

Los delegados, internuncios y nuncios que vivieron en Costa Rica fueron personajes que se caracterizaron por cumplir una doble función para Roma, una diplomática y otra religiosa. En la diplomática se puede hablar de un éxito completo, gracias a que nunca se vieron vinculados a problemas serios de carácter internacional, y más bien buscaban soluciones a las disputas que se dieron entre los gobiernos de la zona. Además, lograron uno de los principales cometidos que Roma les solicitaba, el cual era crear y fortalecer las relaciones entre esta y todas las naciones del área. Muestra de ello fue el nombramiento de Mons, Carlo Chiarlo en 1932, quien llegó con el título de internuncio apostólico para Costa Rica, Honduras, Nicaragua, El Salvador, Panamá y delegado apostólico para Guatemala.

En 1933, por disposición del Papa, se crearon dos nunciaturas en Centroamérica. Una de ellas solo para Nicaragua, Panamá y Costa Rica, en la cual el nuncio fue el mismo Chiarlo; y la segunda, para Honduras y El Salvador, y al mismo tiempo esta era delegación apostólica para Guatemala, pero encabezada por Mons. Alberto Levame. Esto mostró un claro avance, ya en 1908, Mons. Cagliero llegó solo con credenciales para Costa Rica y con la tarea expresa de conseguir el reconocimiento de Honduras y Nicaragua; 25 años después existían dos nunciaturas que abarcaban los 6 países de la zona.

Desde el punto de vista religioso, se puede decir que el trabajo de estos hombres fue realizado de acuerdo con los designios de Roma, eran informantes constantes no solo de las situaciones sociales de los países, sino también de índole religioso. Ellos tuvieron mucho que ver en la aparición de las nuevas provincias eclesiásticas de Centroamérica entre 1908 y 1936, debido a que fueron los productores de los estudios geográficos, demográficos, económicos y sociales para las divisiones que se dieron. De igual manera, fueron los encargados de corroborar y desmentir la información que llegaba a Roma. Por último, se convirtieron en los supervisores de la feligresía, clero y episcopado centroamericano, fuera o no este su principal propósito.

Por último, todo este papel desempeñado por los enviados papales debe ser entendido bajo una realidad social que vivía la zona. La llegada de los liberales al poder y su intención de secularizar las sociedades se unió a la intención de la Santa Sede de consolidar la romanización del clero y de los feligreses. 
A pesar de que el proceso para conseguir esta secularización conllevó diferentes etapas en cada país de la zona el accionar constante de los delegados papales fue una constante en toda la región. Estos hombres, para evitar una separación total entre el Estado y la Iglesia, procuraron siempre tener relaciones cordiales con los Estados en los cuales eran los representantes del Papa, objetivo que se cumplió a cabalidad.

De igual manera, se incentivó el sentimiento de unión del clero y los feligreses con el Obispo de Roma, esto mediante la constante actividad de solicitar el acatamiento a lo decretado y establecido por el Papa, así como impulsar celebraciones religiosas vinculadas al crecimiento de la autoridad moral del Obispo de Roma. Un ejemplo de estas son las fiestas al Corazón de Jesús, a San José, al Santísimo Sacramento, a San Pedro y San Pablo, a Cristo Rey, el Santo Rosario. Además, se recaudaban fondos para Óbolo de San Pedro y se entregaba la bendición del Papa para ciertas ocasiones especiales.

Esto sin duda con el pasar de los años provocó que la población se sintiera más unida y cercana a una figura que por mucho tiempo fue lejana y desconocida. Evidencia de ello fueron los recibimientos dados a los enviados papales al llegar a un país del área, donde se les organizaban fiestas en su honor y desfiles multitudinarios por los fieles a causa de ser el representante del Papa.

\section{ABSTRACT \\ Costa Rica in the geopolitics of the Holy See \\ Papal representation in Central America between 1908 and 1936}

This article presents the reader with a view of the origin, development and role of papacy representations sent to Central America by the Holly See between 1908 and 1936. An analysis of the reasons, purposes and tasks Rome assigned to these messengers is presented. Through their reports, it will be explained how Central America was analyzed from various points of view: economic, social, cultural, military and even electoral. This last aspect allowed the Holly See have a broader and clearer panorama of the situation faced by the region. The period of this study is justified because in 1908 the first apostolic delegation in Central America was created. The study continued up to 1936 since it was the last year documents could be consulted in the Vatican Archive.

Key words: Holly See, papal representation, internunciatura, papal nuncios, Clerical Romanization.

\section{RÉSUMÉ}

Le Costa Rica dans la géopolitique du Saint-Siège. La représentation du Pape en Amérique Centrale entre 1908 et 1936

Cet article offre au lecteur un panorama de l'origine, du développement et du rôle des représentants du Pape envoyés par le Saint-Siège en Amérique Latine entre 1908 et 1936. On analysera quelles ont été les motifs, les fonctions et les tâches que Rome assignait à ces délégués. On exposera comment, à travers leurs rapports, l'Amérique Centrale était analysée à partir de divers points de vue : économiques, sociaux, culturels, militaires et politiques. Ceci a permis au Saint-Siège d'avoir un aperçu global et clair des situations auxquelles la région faisait face. $\mathrm{La}$ 
période d'étude est justifiée parce que la première délégation apostolique en Amérique Centrale a été créée en 1908, et c'est jusqu'en 1936, la dernière année, que les documents des Archives du Vatican peuvent être consultés.

Mots-Clés : Saint-Siège, envoyés du Pape, internonciature, nonces et romanisation du clergé.

\section{Referencias bibliográficas}

Alberigo, G. (ed) (1993). Historia de los concilios Ecuménicos. Salamanca, Editoral Sígueme.

Arbolda, C. (2006 enero-junio) Laicismo y Laicidad en Colombia. Cuestiones Teológicas. Vol. 33, No. 79. 69-95.

Azzi, R. (1994) A neocristandade um projeto restaurador. (História do pensamento católico non Brasil; v.5) Sao Paulo, Paulus.

Bendaña, R. (2011, V ed.) La Iglesia en la historia de Guatemala (1500-200). Ciudad de Guatemala, Artemis Editer.

Blancarte, R. (Coor). (2008) Los Retos de la Laicidad y la Secularización en el Mundo Contemporáneo. México: El Colegio de México.

Blanco, R. (1984). Obispos, Arzobispos y Representantes de la Santa Sede en Costa Rica. San José: EUNED.

Calvo, C. (1980). Rafael Yglesias Castro. San José: Imprenta Nacional.

Codex Iuris C. (1917, versión 1996). Città del Vaticano: Librería Editrice Vaticana.

DI Stefano, R. (2011 II semestre) El pacto laico argentino (1880-1920). Historia y Religión. Recuperado de: http://historiayreligion.com/2012/03/di-stefano-roberto-el-pactolaico-argentino-1880-1920-polhis-8-2\%C2\%BA-semestre-de-2011-80-89/. 1-20.

Feldkamp, M. (2004). La diplomacia pontificia. Madrid. Biblioteca de Autores Cristianos.

Fraile, G. (1966) Historia de la filosofía. Tomo II. Madrid, BAC. Recuperado de: http:// www.catholic-hierarchy.org/bishop/bmegl.html

Martina, G. (1974). La Iglesia de Lutero a Nuestros días. III Tomo, Época del Liberalismo. Madrid, Ediciones Cristiandad.

Martina, G. (1994). La prima missione pontifícia nell'America Latina

Archivum Historiae Pontificiae. N ${ }^{\circ}$ 32. Roma: Pontificia Universitas Greogoriana, Facultas Historiae Ecclesiasticae. 149-193.

Molina, I. (1989) El 89 de Costa Rica: otra interpretación del levantamiento del 7 de Noviembre. Revista de Historia de Costa Rica. № 20 San José. EUNA-EUCR. 177-192.

Picado, M. (1993) "Los Concordatos celebrados entre los países de Centro América y la Santa Sede". Revista de Historia (Costa Rica) No 28, julio-diciembre. San José: EUNA-EUCR. 207-232.

Rusconi, R. (2010). Santo Padre. La santità del papa da san Pietro a Giovanni Paolo II. Roma, Viella. 
Sáenz. F., Fernández J. y Muñoz M. G. (2001). Las Primeras Damas de Costa Rica. San José, ICE.

Salazar, O. (2003). El apogeo de la república Liberal en Costa Rica 1870-1914. San José, EUCR.

Sanabria, V. Delegaciones Apostólicas en el siglo XIX. En: PICADO, Miguel y José Alberto Quirós (eds) (2006). Estudios Historiográficos de Monseñor Victor Manuel Sanabria. San José, EUNED.

Sánchez, E. (2013). La participación político-partidista de la Iglesia: el Partido Unión Católica y sus estrategias de movilización política en el marco del conflicto entre la Iglesia católica y el estado liberal en Costa Rica (1889-1898). Tesis de Maestría, San Pedro: Universidad de Costa Rica.

Sandí, J. A. (2012) Estado e Iglesia católica en Costa Rica 1850-1920; en los procesos de control del espacio geográfico y la creación de un modelo costarricense. Heredia, UNA.

\section{Fuentes documentales:}

\section{Archivio della Sacra Congregazione degli Affari Ecclesiastici Straordinari:}

1. Costa Rica. 1865-1873. Fasc. 1. Pos. 42-43, f. 3.

2. Costa Rica. 1884-1885. Fasc. 7. Pos. 58, f. 14.

3. Costa Rica 1892.1893. Fasc. 18. Pos. 76-81, ff. 69-74.

\section{Archivio Segreto Vaticano: Archivio della Nunziatura dell'America Centrale:}

4. Indice 1156. Archivio Vaticano Segreto: Archivio della Nunziatura dell'America Centrale.

5. Fasc. 1. Ff 49-53.

6. Fasc. 17 Segretaria di Stato. Ff. 16-19v y 93-94.

7. Fasc. 25 Congregazione Concistoriale. Ff. 59-64.

8. Fasc. 28 Congregazione Concistoriale. F. 69.

9. Fasc. 32. Diocesi di San Jose Ff. 73-75

10. Fasc. 85 Governo di Nicaragua. Ff. 55-57.

11. Fasc. 95 Corrispondenza con i governi dell'America Centrale. Ff. 2-3. 